\title{
CORRIGENDUM
}

\section{FOUR PRECERAMIC POINTS NEWLY DISCOVERED IN BELIZE: A COMMENT ON STEMP ET AL. (2016:279-299) - CORRIGENDUM}

\author{
W. James Stemp, Jaime J. Awe, M. Kathryn Brown, Eleanor Harrison-Buck,
} Christophe G. B. Helmke, Gabriel D. Wrobel, and Jason Yaeger

DOI: https://doi.org/10.1017/laq.2017.82, Published by Cambridge University Press, 14 December 2017.

In the original publication of this article, the title was printed as "Four Preceramic Points Newly Discovered in Belize: A Comment on Stemp et al. (1996:279-299)." The article has been updated to the correct title. The authors apologize for this error.

\section{Reference}

Stemp, W. James, Jaime J. Awe, M. Kathryn Brown, Eleanor Harrison-Buck, Christoph G. B. Helmke, Gabriel D. Wrobel, and Jason Yaeger

2017. Four Preceramic Points Newly Discovered in Belize: A Comment on Stemp et al. (2016:279-299). Latin American Antiquity, doi:10.1017/laq.2017.82. 